\title{
The multiform clinic of the localized/systemic BCGitis under Real-Life conditions of an academic private practice
}

\author{
Bohm WDU'*, Wenzel $S^{2}$, and Koch $\mathbf{R}^{3}$ \\ ${ }^{1}$ Academic Private practice for Urology Hospital St.Joseph-Stift Dresden, Germany \\ ${ }^{2}$ Clinic for Urology, University clinic Dresden, Germany \\ ${ }^{3}$ Institute for Biometry and Medical Statistic, Technical University Dresden, Germany
}

\section{Introduction}

The non-muscle-invasive bladder cancer (NMIBC) with an intermediate or high-risk profile needs strictly to be treated by an adjuvant risk-adapted Instillation therapy of the bladder. The intermediate risk group is treated preferentially with Mitomycin C the high-risk group with attenuated living Mycobacteria tuberculosis var. Bovis (BCG). The indication is implemented in the guidelines for pTa-pT1G3/-Tis, multiple pT1G2 and the special case of isolated pTis. The application frequency during maintenance therapy is determined, but still discussed

Within this context it is mandatory that there are precise data concerning the resected tumor and its risk profile to avoid arbitrary courses.

The primary aim of this study was to show the tolerable symptomatology as well as the direct adverse events that cause complications during the therapeutic management - from a personal point of view.

\section{Methods/Study design}

All of our 106 patients underwent a primary TURB. The single application of Mitomycin C postoperative was inconsistently. Unifocal low risk tumors were excluded from our study.

A secondary TURB followed after an interval of 4-6 weeks partly with photodynamic diagnostic. Another 4 weeks later we started with the inductive cycle of BCG application versus Mitomycin C (1 application per week for 6 weeks). The BCG preparation depended on the current availability of the different preparations (BCG-RIVM, BCG TICE, BCG CONNAUGHT). The different Mitomycin C preparations were Mito-medac ${ }^{\circledR}$, Mito-extra ${ }^{\circledR}$, Urocin ${ }^{\circledR}$. The decision of using BCG or Mitomycin C depended on the latest guidelines and the case history of the patient (comorbidities, tuberculosis in the past, immunodeficiency or patients will). During maintenance with BCG we applicated 3 more doses every 3,6 and 12 months. If possible, we tried to repeat the doses after 18, 24, 30 and 36 months. Mitomycin was given continuously every 4 weeks for 2 years.

In case of a repeatedly intolerance or clinical ineffectiveness and even unavailability (especially BCG) a switch to the other treatment arm was allowed. The statistical analysis (Kaplan-Meyer-Analysis, Mantel-Haenszel-estimation of the Hazard Ratio, Log-Rank-Test) was concentrated on the primary classification and the longest term in the treatment arm.
The retrospective structured data analysis included the 106 patients within an observation period from January 2006 till December 2016. The numeric summary is found in Table 1 .

The study results - minor and major adverse events under therapy

The urogenital-localized manifestation of symptoms is differentiated from the systemic manifestation. The minor complications like dysuria (MMC), urgency, (micro-)hematuria, leucocyturia, fever up to $48 \mathrm{~h}$, weakness and night sweat (BCG) during instillation therapy are international consistently reported and accepted - and interpreted as proof of effectiveness [1,2],

In our study we observed $34,7 \%$ adverse events in the MMC group and $78,4 \%$ in the BCG group. This difference is highly noticeable and much higher than in other reported studies. 13 patients $(38,2 \%)$ had to switch from the BCG group to the MMC group because of toxicity during maintenance therapy. Only 4 patients $(5,6 \%)$ in the MMC group had to break up therapy because of toxicity. A fact we also interpreted as a hint for the discrepant toxicity profile $[3,4]$.

This discrepancy was even more obvious when we compared the major adverse events for MMC (1,4\%) and BCG (43,2\%) - see Table 2. A separate compilation of these adverse events is shown in Table 3. In our study the period of time between instillation therapy and diagnosis of an adverse event ranged from 2 to 12 months. Some examples of such clinical events were published by us recently online (3), including the diagnostic and therapeutic procedures.

\section{The study results - the oncological outcome}

The oncological outcome is summarized in Table 2. In opposition to the high toxicity differences between both arms, the tumor remission rates are comparable in both arms within their indication spectrum. This comparability is shown for the progression rate as well as for the cystectomy rate (13\%). 5 of the 106 patients $(4,7 \%)$ died of tumor progression - in 2 cases because of a urothelial tumor of the kidney [5].

In our study we intentionally did not randomize our patients, so that we can only estimate the overall survival by the date of their primary

*Correspondence to: Wolf-Diether U. Bohm Academic Private practice for Urology Hospital St.Joseph-Stift Dresden, Comeniusstrasse 50A, 01309 Germany, E-mail: dr.wolf-diether.boehm@gmx.de

Received: March 26, 2018; Accepted: April 09, 2018; Published: April 11, 2018 
TURB (Figures 1 and 2). So, we did not see a statistically significance but a medical significance regarding the clinical equality. Our analysis for the tumor specific survival (Competing-risk analysis, Pepe-Moritest) showed for the 5-year-follow-up an equivalence of both study groups - admittedly with a low power for this study [6].

The following analysis of the comorbidity-dependent survivals shows a divergence between two groups - to the disadvantage of the MMC group (Figure 3). The reason therefor might be that choosing the treatment modality might be significantly affected by the comorbidity of the patient [7].

\section{Conclusion}

Under real life circumstances of a private practice we analyzed retrospectively the adjuvant treatment of the non-muscle invasive bladder cancer with BCG and MMC regarding the appearance and variance of the medicinal adverse events.

Table 1. Baseline - characteristics of the 106 patients $\left({ }^{1}\right.$ mito-medac $\left(\mathbb{R}\right.$, Urocin ${ }^{\circledR},{ }^{2}$ BCGmedac ${ }^{\circledR}$, Immucyst ${ }^{\circledR}$, OncoTICE ${ }^{\circledR},{ }^{3}$ mito-extra ${ }^{\circledR}$, IR intermediate-risk, HR high-risk nach EORTC)

\begin{tabular}{|c|c|c|c|c|c|c|c|}
\hline & \multirow{2}{*}{\multicolumn{2}{|c|}{ Patients }} & \multirow{3}{*}{\begin{tabular}{|c|} 
Age \\
$\begin{array}{c}\varnothing \\
\text { (Range) }\end{array}$ \\
\end{tabular}} & \multicolumn{4}{|c|}{$\begin{array}{c}\text { Indications } \\
\text { (pTaG1 mult., pTaG2/3, pT1, pTis) }\end{array}$} \\
\hline & & & & \multicolumn{2}{|c|}{ IR } & \multicolumn{2}{|c|}{ HR } \\
\hline & $\mathbf{n}$ & $\%$ & & $\mathbf{n}$ & $\%$ & $\mathbf{n}$ & $\%$ \\
\hline Mitomycin $\mathbf{C}^{1}$ & 34 & 32.1 & $\begin{array}{l}74.71 \\
(48-92)\end{array}$ & 38 & 52.8 & 34 & 47.2 \\
\hline $\mathbf{B C G}^{2}$ & 72 & 67.9 & $\begin{array}{c}76-12 \\
(54-92)\end{array}$ & 3 & 8.8 & 31 & 91.2 \\
\hline
\end{tabular}

Table 2. Toxicity and clinical trends. (REM remission, switch treatment arm, PR progression, Cx early cystectomy, ${ }^{1}$ mito-medac $\left(\right.$, ${ }^{1}$ Urocin $\AA$, ${ }^{2}$ BCG-medac $\left({ }^{2}\right.$ Immucyst $($, OncoTICE ()

\begin{tabular}{|c|c|c|c|c|c|c|c|c|c|}
\hline & \multicolumn{4}{|c|}{ Adverse Events } & \multicolumn{2}{|c|}{ Termination } & \multicolumn{3}{|c|}{ Outcome } \\
\hline & \multicolumn{2}{|c|}{ Minor } & \multicolumn{2}{|c|}{ Major } & $\mathbf{n}$ & $\%$ & Status & $\mathbf{n}$ & $\%$ \\
\hline & $\mathrm{n}$ & $\%$ & $\mathrm{n}$ & $\%$ & & & REM & 61 & 84.7 \\
\hline \multirow{4}{*}{ Mitomycin $\mathrm{C}^{1}$} & \multirow{4}{*}{25} & \multirow{4}{*}{34.7} & \multirow{4}{*}{1} & \multirow{4}{*}{1.4} & \multirow{4}{*}{5} & \multirow{4}{*}{6.9} & switch & 4 & 5.6 \\
\hline & & & & & & & PR & 9 & 12.5 \\
\hline & & & & & & & $\mathrm{Cx}$ & 9 & 12.5 \\
\hline & & & & & & & $\begin{array}{c}\text { Tumorspecific } \\
\text { death }\end{array}$ & 4 & 5.6 \\
\hline \multirow{5}{*}{$\mathrm{BCG}^{2}$} & \multirow{5}{*}{29} & \multirow{5}{*}{78.4} & \multirow{5}{*}{16} & \multirow{5}{*}{43.2} & \multirow{5}{*}{7} & \multirow{5}{*}{18.9} & REM & 38 & 82.4 \\
\hline & & & & & & & switch & 13 & 39.4 \\
\hline & & & & & & & PR & 4 & 11.8 \\
\hline & & & & & & & $\mathrm{Cx}$ & 4 & 11.8 \\
\hline & & & & & & & $\begin{array}{c}\text { Tumorspecific } \\
\text { death }\end{array}$ & 1 & 2.9 \\
\hline
\end{tabular}

Table 3. Major - complications under BCG (* Presentation of Clinic, Imaging, Histology)

\begin{tabular}{|l|l|}
\hline Localizations* & n \\
\hline Urogenitally localized & \\
\hline Urocystitis granulomatosa & 5 \\
\hline Low capacity bladder & 1 \\
\hline Epididymo-orchitis & 1 \\
\hline Prostatitis granulomatosa & 4 \\
\hline Distal stricture of the ureter & 2 \\
\hline Systemic manifestation & \\
\hline Pneumonitis & 3 \\
\hline Hepatitis granulomatosa & 1 \\
\hline
\end{tabular}

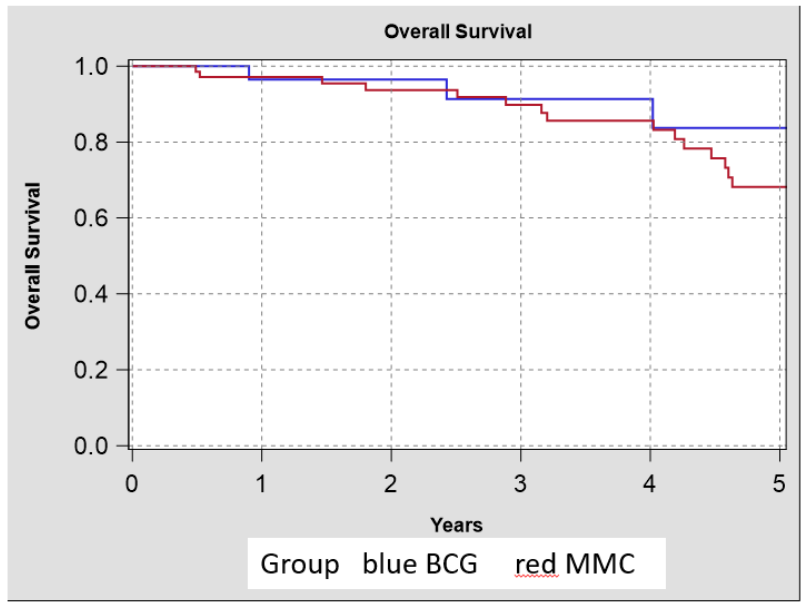

Figure 1. Overall Survival

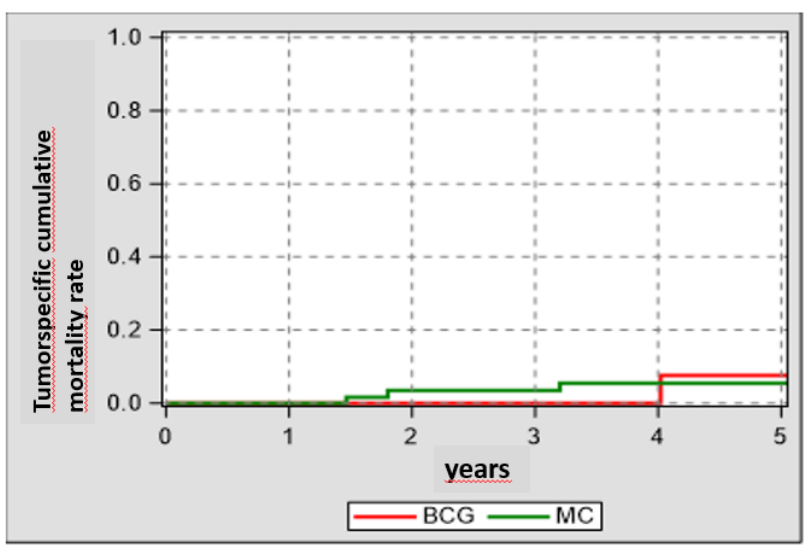

Figure 2. Tumor specific cumulative mortality rate

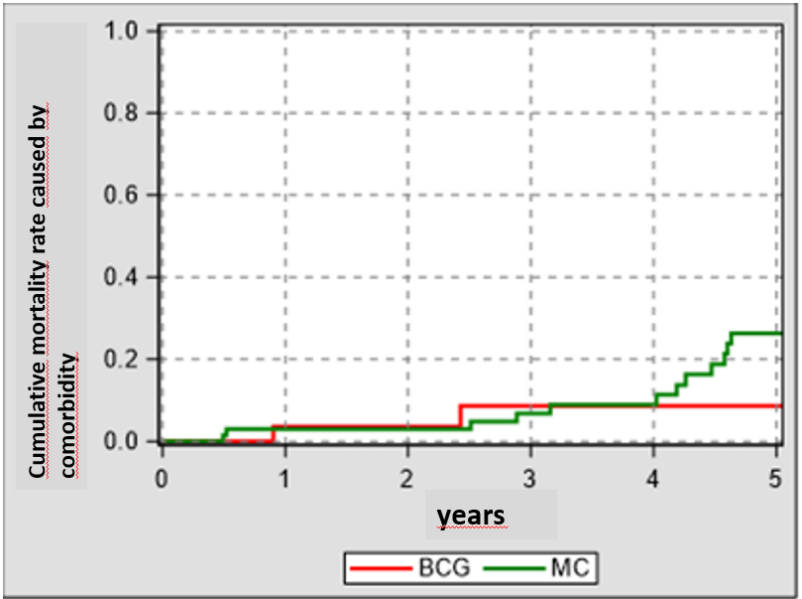

Figure 3. Cumulative mortality rate caused by comorbidity

Even with the strict following of the guidelines regarding frequency and implementation of the therapy we found beside the minor adverse events surprisingly a certain amount of major adverse events within the BCG group that were clinical relevant and that required medicinal or surgical treatment. We recommend further contributions concerning the follow up of individual progresses after granulomatous organ manifestations that should increase evidence. 
In case of a BCG itis the manifestation side determines the further therapy. A granulomatous eosinophil urocystitis should be treated with Isoniacid $300 \mathrm{mg}$ per day for 4 weeks. If this therapy is insufficient, Rifampicin $600 \mathrm{mg}$ per day should be added for another 3 months, If the manifestation is extravesical but urogenital there can also be used a combination therapy of Isoniacid and Ethambutol for 3 months. If there is a hepatic, pulmonary or extra urogenital manifestation with even septic appearance a primary 3-combination-therapy of antitubercular drugs over 6 months is indicated (INH, EMB, RMP) - maybe glucosteroid drugs are necessary as well.

If a longer pause of BCG is necessary, a switch to MMC (40mg or a combination with hyperthermia therapy) or even a cystectomy should be considered.

The use of fluorchinolons with corticosteroids or the preventive therapy with Isoniacid 3 days before instillation, seems nowadays obsolete.

The shown data for the oncological follow up should be seen under the aspect of unequally distributed power in both therapy arms but match the reality in a private practice - admittedly not comparable to a randomized controlled study.

\section{References}

1. Arends TJH, Nativ O, Maffezini M, de Cobelli O, Canepa G, et al (2016) Results of a randomized controlled trial comparing intravesical chemohyperthermia with mitomycin $\mathrm{C}$ versus bacillus Calmette-Guèrin for adjuvant treatment of patients with intermediate- and high-risk non-muscle-invasive bladder cancer. Eur Urol 69: 10461052. [Crossref]

2. Babjuk M, Böhle A, Burger M, Capoun O, Cohen D, et all (2017) EAU guidelines on non-muscle-invasive urothelial carcinoma of the bladder: update 2016. Eur Urol 71: 447-461. [Crossref]

3. Böhm WDU, Koch R, Wenzel S, Wirth MP, Toma M (2018) Zur urogenitalen Klinik der lokalisierten/systemischen BCGitis. Retrospektive Untersuchungen im direkten Vergleich zu Mitomycib C. Der Urologe, published online 02 March 2018, [Crossref]

4. Lebentrau S, May M, Weckermann D, Speck T, Wick AK, Mathew M, Schostak M (2017) Nicht-muskelinvasives Harnblasenkarzinom: Risikostratefizierung und Befundweitergabe. Ergebnisse einer Fragebogenstudie und Vorstellung einer Softwarelösung. Der Urologe 56: 194-201.

5. Martinez-Pineiro L, Portillo JA, Fernandez JM, Zabala JA, Cadiemo I, at el (2015) Maintenance therapy with 3-monthly bacillus Calmette-Guèrin for 3 jears is not superior to standard induction therapy in high-risk non-muscle-invasive urothelial bladder carcinoma: final results of randomised CUETO study 98013. Eur Urol 68: 256262. [Crossref]

6. Pommier JD, Ben Lasfar N, Van Grunderbeeck N, Burdet C, Laouenan C, et al (2015) Complications following intravesical bacillus Calmette-Guerin treatment for bladder cancer: a case series of 22 patients. Infect Dis(Lond) 47: 725-731. [Crossref]

7. Schaberg T, Bauer T, Castell S, Dalhoff K, Detjen A, et all (2012) Empfehlungen zur Therapie, Chemoprävention und Chemoprophylaxe der Tuberkulose im Erwachsenenund Kindesalter. Deutsches Zentralkomitee zur Bekämpfung der Tuberkulose (DZK), Deutsche Gesellschaft für Pneumologie und Beatmungsmedizin (DGP). Pulmologie 66: 133-171.

Copyright: (2018 Bohm WDU. This is an open-access article distributed under the terms of the Creative Commons Attribution License, which permits unrestricted use, distribution, and reproduction in any medium, provided the original author and source are credited. 